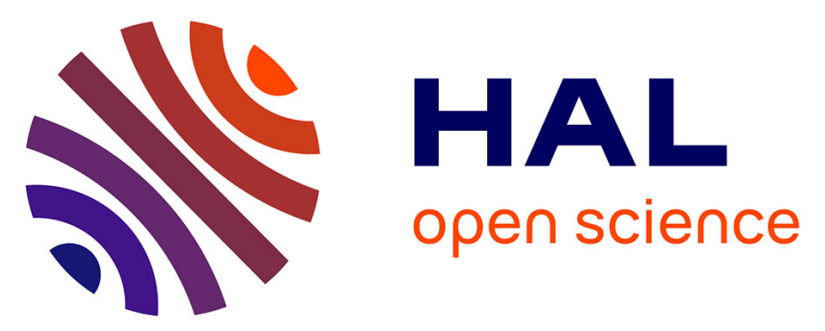

\title{
Bulgecin A: The Key to a Broad-Spectrum Inhibitor That Targets Lytic Transglycosylases.
}

Allison H. Williams, Richard Wheeler, Constance Thiriau, Ahmed Haouz, Muhamed-Kheir Taha, Ivo G. Boneca

\section{To cite this version:}

Allison H. Williams, Richard Wheeler, Constance Thiriau, Ahmed Haouz, Muhamed-Kheir Taha, et al.. Bulgecin A: The Key to a Broad-Spectrum Inhibitor That Targets Lytic Transglycosylases.. Antibiotics, 2017, 6 (1), pp.8. 10.3390/antibiotics6010008 . pasteur-02013262

\section{HAL Id: pasteur-02013262}

\section{https://hal-pasteur.archives-ouvertes.fr/pasteur-02013262}

Submitted on 10 Feb 2019

HAL is a multi-disciplinary open access archive for the deposit and dissemination of scientific research documents, whether they are published or not. The documents may come from teaching and research institutions in France or abroad, or from public or private research centers.
L'archive ouverte pluridisciplinaire HAL, est destinée au dépôt et à la diffusion de documents scientifiques de niveau recherche, publiés ou non, émanant des établissements d'enseignement et de recherche français ou étrangers, des laboratoires publics ou privés.

\section{(ㅇ)(1) $\$$}

Distributed under a Creative Commons Attribution - NonCommercial - NoDerivatives| 4.0 
Article

\title{
Bulgecin A: The Key to a Broad-Spectrum Inhibitor That Targets Lytic Transglycosylases
}

\author{
Allison H. Williams 1,2,*, Richard Wheeler ${ }^{1,2}$, Constance Thiriau ${ }^{1,2}$, Ahmed Haouz ${ }^{3}$, \\ Muhamed-Kheir Taha ${ }^{4}$ and Ivo G. Boneca ${ }^{1,2, *}$ \\ 1 Institut Pasteur, Unité Biologie et génétique de la paroi bactérienne, Dept. Microbiologie, 28 Rue du \\ Dr. Roux, 75015 Paris, France; richard.wheeler@pasteur.fr (R.W.); constancethiriau@hotmail.com (C.T.) \\ 2 Institut National de la santé et de la Recherche Médicale (INSERM), Groupe Avenir, 75015 Paris, France \\ 3 Institut Pasteur, CNRS-UMR3528, Plate-forme de Cristallographie, 25 Rue Dr. Roux, 75724 Paris, France; \\ ahmed.haouz@pasteur.fr \\ 4 Institut Pasteur, Unité des Infection Bactériennes Invasives, Dept. Infection et Epidémiologie, \\ 28 Rue du Dr. Roux, 75015 Paris, France; mktaha@pasteur.fr \\ * Correspondence: awilliam@pasteur.fr (A.H.W.); bonecai@pasteur.fr (I.G.B.) \\ Academic Editor: Waldemar Vollmer \\ Received: 19 December 2016; Accepted: 13 February 2017; Published: 22 February 2017
}

\begin{abstract}
Lytic transglycosylases (Lts) are involved in recycling, cell division, and metabolism of the peptidoglycan. They have been understudied for their usefulness as potential antibacterial targets due to their high redundancy in Gram-negative bacteria. Bulgecin A is an $O$-sulphonated glycopeptide that targets primarily soluble lytic tranglycosylases (Slt). It has been shown that bulgecin A increases the efficacy of $\beta$-lactams that target penicillin bindings proteins (PBPs). Here, we present the high-resolution crystal structure of LtgA from Neisseria meningitidis strain MC58, a membrane bound homolog of Escherichia coli Slt, in complex with bulgecin A. The LtgA-bulgecin A complex reveals the mechanism of inhibition by bulgecin $\mathrm{A}$ at near atomic resolution. We further demonstrate that bulgecin A is not only a potent inhibitor of LtgA, but most importantly, it restores the efficacy of $\beta$-lactam antibiotics in strains of $N$. meningitidis and Neisseria gonorrhoeae that have reduced susceptibility to $\beta$-lactams. This is particularly relevant for $N$. gonorrhoeae where no vaccines are available. This work illustrates how best to target dangerous pathogens using a multiple drug target approach, a new and alternative approach to fighting antibiotic resistance.
\end{abstract}

Keywords: peptidoglycan; Neisseria; bulgecin; lytic transglycosylase; beta-lactam

\section{Lytic Transglycosylases (Lts) as New Antibiotic Targets}

It has been clear since the 1960s that treatment of bacterial infections with $\beta$-lactams has consequently given rise to highly resistant bacteria. Since the 1990s, there has been a surge in antibiotic resistance with no new viable targets identified [1]. The problem of antibiotic resistance has been compounded by the lack of discovery of new classes of broad-spectrum antibiotics. The response to the antibiotic resistance crisis has led to the creation of new synthetic analogs that are largely based on existing treatments [2]. Current dogma suggests that $\beta$-lactams, the most widely used class of antibiotic, disrupt the delicate balance that occurs between penicillin binding proteins (PBPs) and lytic transglycosylases (Lts) [3]. Recently, it was demonstrated that $\beta$-lactams do much more than just inhibit PBPs, but also disable the peptidoglycan (PG) biosynthetic machinery with deleterious outcomes for the bacteria [3]. The effectiveness of $\beta$-lactams as a treatment against bacterial infections revolutionized medicine. This success is threatened by the alarming rise of resistance to $\beta$-lactam antibiotics.

The peptidoglycan (PG) in Gram-negative bacteria is a thin sacculus composed of glycan strands cross-linked by short stem peptides that surround the cell. PG is crucial in maintaining bacterial shape 
and rigidity against osmotic pressure, and enzymes involved in the biosynthesis and remodeling of the PG are amongst the best targets for antibiotics [2]. Lts are intricately involved in the metabolism of the PG. These enzymes cleave the $\beta$-1,4-glycosidic bond between the $\mathrm{N}$-acetylmuramic acid (MurNAc) and $\mathrm{N}$-acetylglucosamine (GlcNAc) residues [4-10]. They are space-making autolysins that permit the insertion of newly synthesized PG material during growth, remodeling, and recycling of the cell wall [4-10]. Escherichia coli recycles a majority of their PG fragments, however, both N. meningitidis and N. gonorrhoeae release cytotoxic PG fragments that are detected by the host $[11,12]$. $N$. gonorrhoeae releases more PG fragments than other Gram-negative bacteria, including other Neisseria species [13]. Released PG fragments are known to induce a Nod1-dependent inflammatory response [14-17]. Blocking the release of cytotoxic PG fragments could be a novel path toward anti-virulence development. This approach could have a profound impact on the treatment of Gram-negative pathogenic infections.

Similar to PBPs, Lts are highly redundant enzymes. E. coli has eight Lts, seven that are membrane bound (MltA, MltB, MltC, MltD, MltE, MltF, MltG) and one that is a soluble periplasmic enzyme (soluble lytic tranglycosylase (Slt)70) [18]. Neisseria species have five identified Lts (LtgA, LtgB, LtgC, $\operatorname{LtgD}$, and LtgE) that have been previously characterized [19-21]. Recent studies have started to unravel the functional reasons for the redundancy of Lts across Gram-negative bacteria. For example, it is known that deletion of $\operatorname{ltg} A$ and $\operatorname{ltg} D$ in $N$. gonorrhoeae eliminates the release of cytotoxic PG monomers $[11,20]$. More recently, it was revealed that LtgA primarily localizes at the septum, while LtgD is localized around the cell. This suggests that LtgA produces PG monomers that are largely taken into the cytoplasm for recycling, and LtgD produces PG monomers that are released [22]. Additionally, MltE, a membrane bound Lt from E. coli, was recently shown to be involved in the assembly of the type VI secretion system (T6SS) in enteroaggregative E. coli [23]. MltE in the presence of an inhibitor, bulgecin A, affects the function of the T6SS, suggesting a more specialized role in the bacteria cell wall [23].

Lts engage in protein-protein interactions with enzymes involved in PG synthesis, such as PBPs, amidases, and PG hydrolases [18]. Although the precise role of Lts in these PG assemblies is unclear, altogether, these enzymes sustain growth and division of the bacteria without disrupting the structural integrity of the cell wall [24-28]. To date, nearly all the Lts from E. coli have been structurally characterized. Lts have distinct overall secondary structural differences, however, the catalytic domain, architecture of the active site, enzymatic activities, and substrate specificities are uniquely conserved [29]. This conservation makes Lts natural targets for broad-spectrum inhibitors that target their enzymatic activities.

Based primarily on the crystal structures of Slt70 and Slt35, it is proposed that Lts utilize a single catalytic residue playing the role of an acid and then a base (Figure 1a) [9,29-32]. Mechanistically, Lts are known to use a single catalytic glutamate or aspartate in a simple acid then base catalysis (Figure 1a). In the absence of a second catalytic residue in the active site of Lts, these enzymes likely proceed via anachimeric assistance of the MurNAc 2-acetamido group and formation of the oxazolinium ion intermediate [31]. Previous studies deciphering the mechanistic details of Lts revealed that $\beta$-hexosaminidase inhibitor (NAG-thiazoline) inhibits the activity of Lts. This seminal study was the first to establish a direct link between the formation of 1,6-anhydromuramoyl and the oxazolinium ion intermediate [31]. In the second half of the mechanism, the catalytic glutamate acts as a general base to abstract the proton from the C-6 hydroxyl, leading to its nucleophilic attack on the anomeric center and the formation of a 1,6-anhydromuramic acid product [31]. 

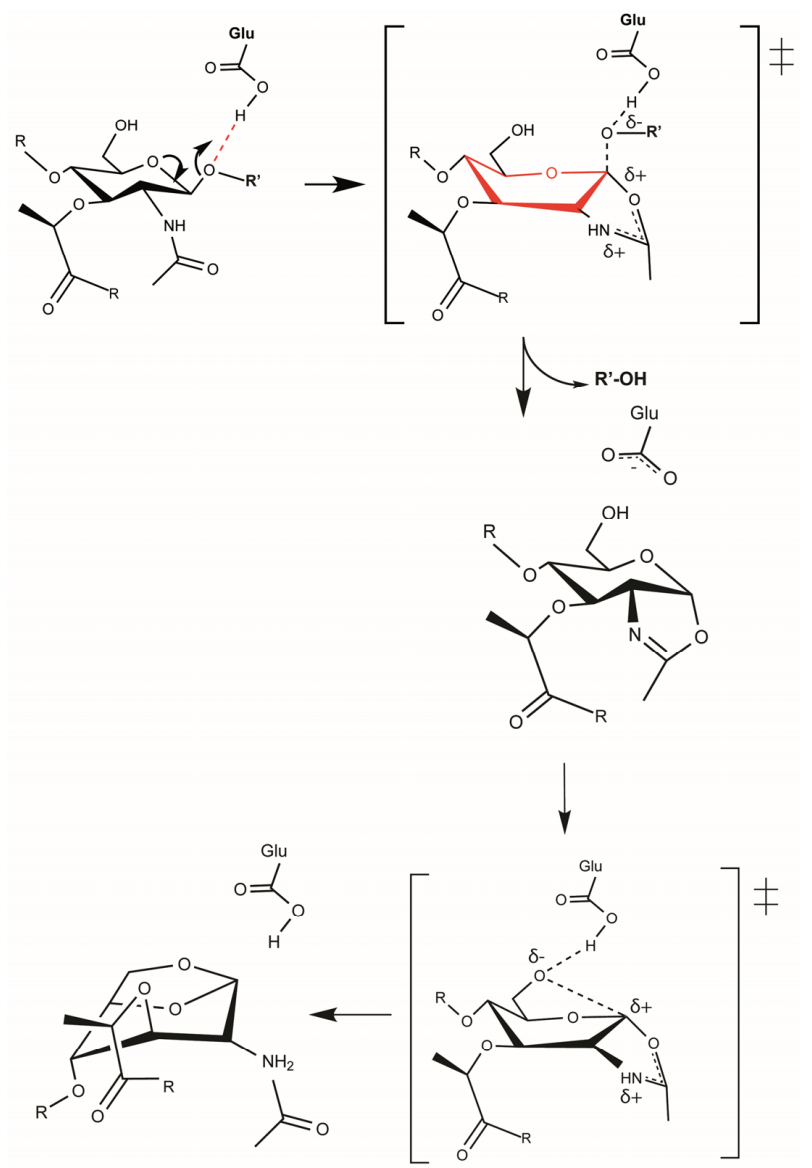

(a)

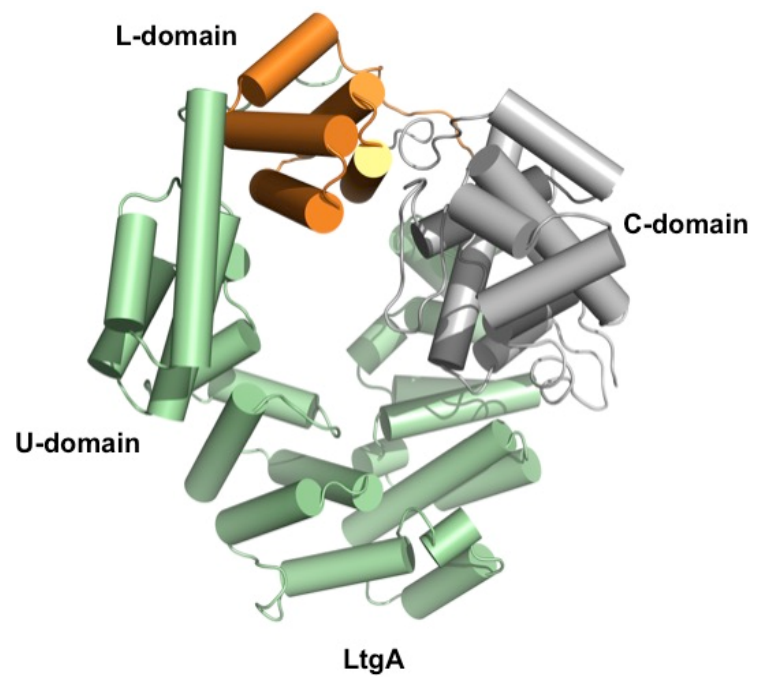

(b)

Figure 1. (a) Proposed catalytic mechanism of lytic transglycosylases (Lts). Lts use a single catalytic glutamate or aspartate in a simple acid and then base catalysis. In the absence of a second catalytic residue in the active site, these enzymes proceed via anachimeric assistance of the $\mathrm{N}$-acetylmuramic acid (MurNAc) 2-acetamido group and formation of the oxazolinium ion intermediate [31]; (b) Overall structure of LtgA. LtgA has three domains: U (green), L (orange) and C (grey). Structure is displayed in a front view. The helices are represented as cylinders. 
It has been demonstrated that bacteria devoid of Slts are sensitive to $\beta$-lactams and display a bulging phenotype prior to bacteriolysis [33]. The same effect is seen when $\beta$-lactams are combined with bulgecin A, an O-sulfonated glycopeptide with known antibacterial activity toward Slt70 [33,34]. Previous structural and biochemical evidence shows that bulgecin A specifically targets Slts from E. coli. The synergism between $\beta$-lactams and bulgecin A has previously been demonstrated in E. coli, Helicobacter pylori, Pseudomonas aeruginosa, and Acinetobacter baumannii [33-36].

In Neisseria species, specifically, N. meningitidis and N. gonorrhoeae, reduced susceptibility to $\beta$-lactams is mediated by polymorphism of the pen $A$ gene (encoding PBP2) [37,38]. Penicillin, the most widely used $\beta$-lactam, binds PBPs and inhibits their transpeptidase activity. Modifications in the transpeptidase active site of PBPs results in reduced efficacy of penicillin towards PBPs [37,38]. Patients infected with $N$. meningitidis and $N$. gonorrhoeae, particularly penicillin-resistant strains, could benefit from targeting Lts and PBPs simultaneously in a dual therapy approach.

To evaluate the potential of bulgecin $\mathrm{A}$ as a broad-spectrum inhibitor for Lts, we solved the high-resolution crystal structures of the membrane bound Lt (LtgA) from the Neisseria species in complex with bulgecin A. The near atomic resolution structure of the LtgA-bulgecin A complex shows the complete structure of bulgecin A supported by a well-defined solvent model that clearly shows highly conserved residues interacting directly with bulgecin A and those that are engaged via water mediated interactions. Bulgecin A appears to mimic the oxocarbonium intermediate step in the predicted mechanism of Lts and is most likely competitive with the glycan strand of the PG. The enzymatic, biological, and structural evidence shows that bulgecin A inhibits LtgA. Furthermore, we demonstrate that bulgecin A, combined with $\beta$-Lactams, could be a useful alternative strategy for restoring the efficacy of $\beta$-lactams in resistant strains of $N$. meningitidis and N. gonorrhoeae. This study will facilitate the design of potent, broad-spectrum inhibitors that target Lts.

\section{Results}

\subsection{The Native Structure of $\operatorname{Ltg} A$}

The native structure of LtgA closely resembles its E. coli Slt70 counterpart. We have determined the crystal structure of LtgA lacking the signal sequence (MKHSLPLLAALVLAACSSTN) necessary for its membrane localization (Table 1 and Figure 1b). LtgA is responsible for the release of cytotoxic PG monomers from Neisseria pathogenic species [11,21]. LtgA shares approximately 33\% similarity in the C-terminal domain to its soluble periplasmic E. coli counterpart, Slt70, but is predicted to be an outer-membrane lipoprotein that is localized to the septum of N. gonorrhoeae [9,22] (Figure 1b). Lts belong to the Family 1 of glycoside hydrolases (GH) family 23, and shares sequence similarity to the goose-type lysozyme. Based primarily on the classification of Blackburn and Clarke, family 1 is further subdivided into five subfamilies (1A to 1E). Slt70 and LtgA both belong to family $1 \mathrm{~A}$.

LtgA is a "heart-shaped" highly alpha-superhelical structure consisting of $37 \alpha$-helices (Figure 1b). LtgA has three distinct domains: the C-domain, which is the catalytic domain, and the L and U-domains for which the function is unknown (Figure $1 \mathrm{~b}$ and Figure S1a). The C-domain (colored in grey) is connected to the L-domain by a linker, but is firmly held in place by the $U$ (colored in green) and $\mathrm{L}$ (orange) domains. Unlike the structure of Slt70, the U domain (colored in green) partially overlaps with the L-domain (colored in orange) and completely locks this structure (Figure 1b and Figure S1a,b). 
Table 1. Data-collection and refinement statistics.

\begin{tabular}{|c|c|}
\hline $\begin{array}{l}\text { Data Collection } \\
\text { Ligand Added }\end{array}$ & $\begin{array}{c}\text { LtgA-Bulgecin A } \\
\text { Bulgecin A }\end{array}$ \\
\hline $\begin{array}{c}\text { Data collection } \\
\text { Wavelength }(\AA) \\
\text { Resolution range }(\AA) \\
\text { Space group }\end{array}$ & $\begin{array}{c}0.9795 \\
45.84-1.78(1.567-1.513) \\
P 2{ }_{1}{ }_{2}{ }_{1}{ }_{1}\end{array}$ \\
\hline $\begin{array}{c}\text { Unit-cell parameters } \\
\qquad a(\AA) \\
b(\AA) \\
c(\AA) \\
\sigma\left(^{\circ}\right), \beta\left(^{\circ}\right), \gamma\left(^{\circ}\right)\end{array}$ & $\begin{array}{c}65.83 \\
71.56 \\
121.12 \\
90\end{array}$ \\
\hline $\begin{array}{c}\text { Total reflections } \\
\text { Unique reflections } \\
\text { Multiplicity } \\
\text { Completeness }(\%) \\
\text { Mean } I / \sigma(I) \\
\text { Wilson } B \text { factor }\left(\AA^{2}\right) \\
R_{\text {merge }}{ }^{+}\end{array}$ & $\begin{array}{c}108,346 \\
54,379 \\
2.0(2.0) \\
98.00(84.00) \\
4.46(0.67) \\
21.65 \\
0.1064(1.13)\end{array}$ \\
\hline $\begin{array}{c}\text { Refinement } \\
R_{\text {factor }}{ }^{*} \\
R_{\text {free }}{ }^{*} \\
\text { No. of atoms } \\
\text { No. of waters } \\
\text { No. of protein residues } \\
\text { R.m.s.d., bonds }(\AA) \\
\text { R.m.s.d., angles }\left({ }^{\circ}\right) \\
\text { Ramachandran favored }(\%) \\
\text { Ramachandran outliers }(\%)\end{array}$ & $\begin{array}{c}0.2131(0.3912) \\
0.2570(0.4084) \\
4920 \\
417 \\
577 \\
0.007 \\
0.91 \\
99 \\
1.0\end{array}$ \\
\hline $\begin{array}{c}B \text { factors }\left(\AA^{2}\right) \\
\text { Average } \\
\text { Macromolecules } \\
\text { Ligand } \\
\text { Solvent } \\
\text { All-atom clash score }\end{array}$ & $\begin{array}{c}27.91 \\
27.43 \\
35.00 \\
33.54 \\
2.09\end{array}$ \\
\hline
\end{tabular}

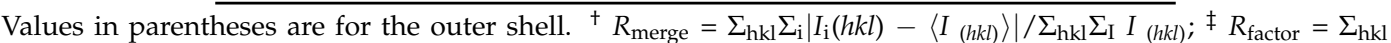
$\left\|F_{\text {obs }}-F_{\text {calc }}\right\| / \Sigma_{\text {hkl }}\left|F_{\text {obs }}\right| ;{ }^{*} R_{\text {free }}$ was computed identically except that all reflections belonged to a test set consisting of a $10 \%$ random selection of the data.

\subsection{Bulgecin A Occupies the Active Site of $\operatorname{Ltg} A$}

Bulgecin A consists of a 4-O-sulfonyl- $N$-acetylglucosamine moiety that is linked by a $\beta 1-4$ glycosidic linkage to a 4-hydroxy-5-(hydroxymethyl)-L-proline (Figure 2a) that terminates with a taurine ( $N$-linked sulfur) moiety. The density for the complete structure of bulgecin A is clear and consistent in the active site of LtgA (Figure S2). Bulgecin A is bound in the region of the active site defined as subsite $-1,-2,-3$, and partially occludes subsite +1 (Figure $2 b, c$ ). The inhibitor is perfectly poised to block the PG glycan strand. An alignment of LtgA catalytic domain with Slt70, $\mathrm{MltE}$, and MltC demonstrates absolute conservation of the active site of LtgA (Figure S3). A docked chito-oligossacharide (chitopentaose) in the active site of LtgA mimics the PG glycan strand (Figure S4). In the active site of $\operatorname{Ltg} \mathrm{A}$, chitopentaose and bulgecin A have overlapping binding sites (Figure $2 \mathrm{~b}-\mathrm{d}$ and Figure S4). This strongly suggests that bulgecin A could be competitive with the PG glycan strand. The 4-O sulfonated group of the GlcNAc residue forms hydrogen bonds through a well-defined solvent model that was not observed in the Slt70-bulgecin structure, because this complex was at a lower resolution (2.8 angstroms) [35] (Figure 2d). The sulfate partially occludes subsite -3 that would block access to the LtgA active site and possibly contribute to the dose-dependent inhibition of bulgecin A. 
The O42 hydroxyl of the sulfur makes an indirect interaction via a water molecule with T504, and is the primary contact of the sulfur group with the active site of $\operatorname{LtgA}$. The sulfate is bound to two additional water molecules that form a continuous network of hydrogen bonds in the active site. These water molecules surrounding bulgecin A in the active site of LtgA potentially contribute to inhibitor stability and efficacy and may be important in substrate binding and catalysis (Figure $2 \mathrm{~d}$ ). There are five water molecules that are in direct contact with bulgecin A. Three are involved in water-mediated interactions with residues in the active site of $\operatorname{Ltg} \mathrm{A}$.

a)

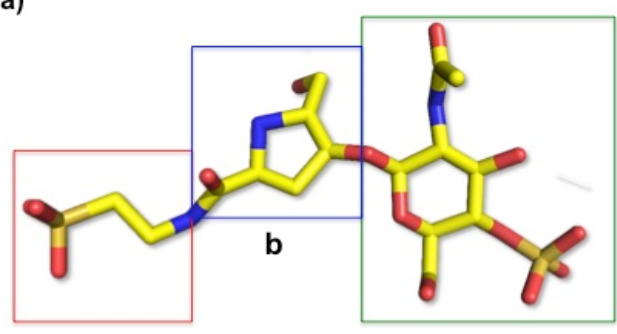

a

C

a Taurine

b 4-hydroxy-5-hydroxymethylproline

c Sulphonated $\mathrm{N}$-acetylglucosamine

b)

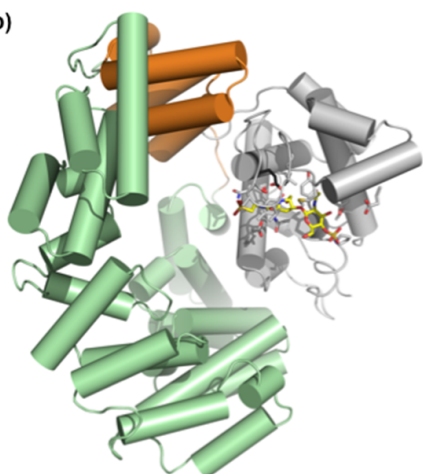

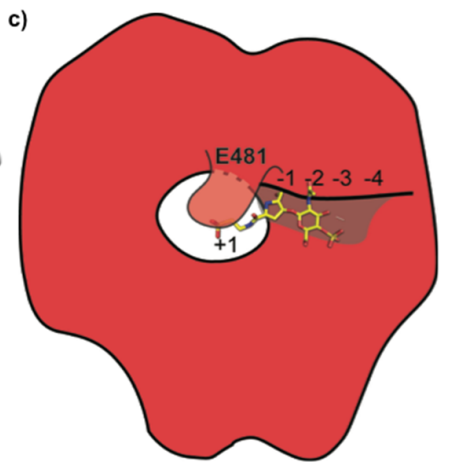

d)

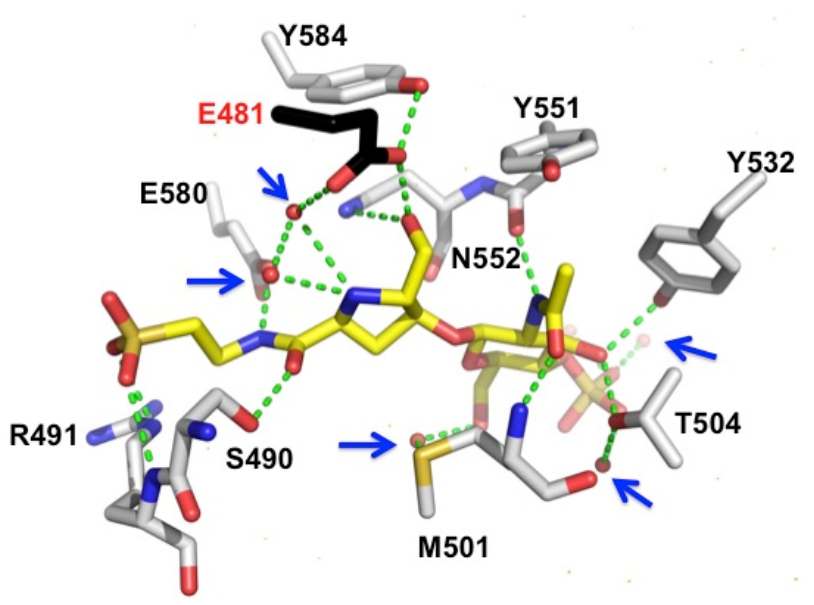

Figure 2. Cont. 
e)

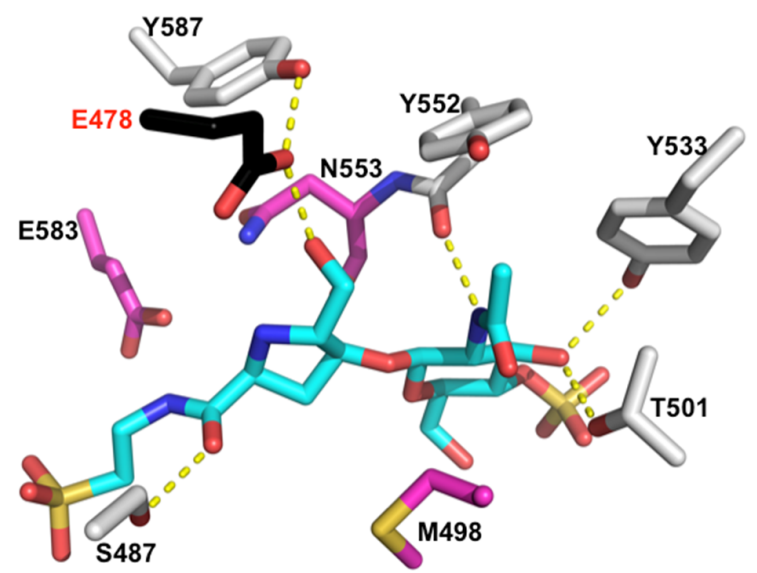

Figure 2. (a) Bulgecin A, a sulphonated $N$-acetyl-D-glucosamine unit linked to a 4-hydroxy-5-hydroxymethylproline ring by a $\beta$-glycosidic linkage. Crystal structure of LtgA in complex with bulgecin A at 1.78 angstroms; (b) Domain organization of LtgA in which the helices are represented by cylinders, and the active site residues are illustrated in a stick model. Active site residues are mainly colored in grey and catalytic residue in black for contrast. Bulgecin A is colored in yellow. In this front view, bulgecin A (yellow) is binding in the putative active site of LtgA; (c) Schematic of bulgecin $\mathrm{A}$ in the active site of $\operatorname{Ltg} \mathrm{A}$; (d) Noncovalent interactions between bulgecin $\mathrm{A}$ and conserved residues in the active site of LtgA (Figure S2 alignment). Water molecules are represented by red spheres and further highlighted with blue arrows; (e) Close-up of the active site of bulgecin A in the active site of Slt70. For contrast to Figure 2d, bulgecin A is colored in blue. Conserved residues that are making interactions in the LtgA-bulgecin A complex are colored in pink. In the soluble lytic tranglycosylases (Slt)70-bulgecin A complex a solvent model is undefined because it is at lower resolution 2.8 angstroms [35].

The GlcNAc residue of bulegecin A is well supported by a network of anionic interactions in the active site of LtgA. In subsite -2 , the GlcNAc residue forms direct hydrogen bonds with the side chains of Y532 and T504 and with the main chain of M501 and Y551 (Figure 2d). The GlcNAc residue is involved in a water-mediated interaction with M501 (Figure 2d). In subsite -1, the hydroxyl-methyl of the proline is directly hydrogen bonded to the OE2 of the catalytic residue E481 and the ND2 of N552. The N1 of proline makes a water mediated interaction with the OE1 of the catalytic residue E481. The backbone carbonyl group of the proline is directly hydrogen bonded to S490. The taurine group of the inhibitor is directly hydrogen bonded to S490 and E580. The OS1 and OS2 of the sulphonated portion of the taurine is directly hydrogen bonded to the main chain and side chain of R491. R491 is unique to LgtA and is not conserved in the Slt70 structure. This demonstrates that the bulgecin A is pliable, to fit different Lt active sites. The taurine part of the inhibitor is well supported in the active site of LtgA, with the sulphonated portion largely accessible by solvent.

\subsection{Bulgecin A Inhibits $\operatorname{Ltg} A$, Slt70, and H. pylori Slt}

Bulgecin A is an effective inhibitor against LtgA. The inhibitory potential of bulgecin A toward Lts was first observed with E. coli Slt70. The mode of inhibition by bulgecin A, as suggested by the Slt70-bulgecin A complex, is consistent with competitive inhibition [35]. It is bound in the substrate-binding site of LtgA and would interfere with binding of the PG glycan strand (Figure 3). The inhibitory potential of bulgecin A toward LtgA was relative to the inhibitor concentration; an increase in the concentration of the bulgecin A results in a comparable decrease in the enzymatic activity of LtgA. Sixty-six percent $( \pm 9.4 \%)$ of the activity of LtgA was lost in the presence of $90 \mu \mathrm{M}$ of bulgecin A (A >60-fold excess of bulgecin A relative to LtgA; Figure 3). This supports the inhibitory potential of bulgecin A toward LtgA in vitro. Previous studies showed that bulgecin A primarily targets Slt70, the soluble Lt of E. coli $[33,35]$. The conservation of the active site of Lts can be exploited for future drug development because bulgecin $\mathrm{A}$ is bound in a conserved active site groove that is aligned with conserved residues (Figure 4a,b and Figure S5). 


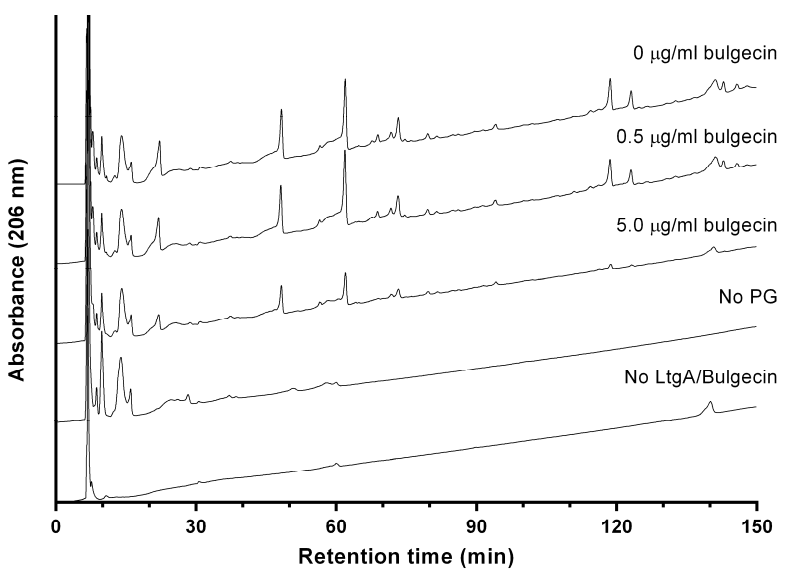

a

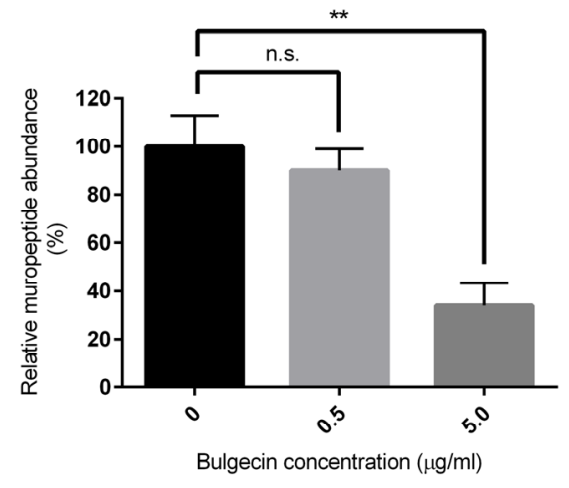

$\mathrm{b}$

Figure 3. Inhibition of LtgA activity by Bulgecin A. (a) Reversed-phase (RP)-HPLC analysis of muropeptides released by LtgA digestion in the presence or absence of bulgecin A $(0 \mu \mathrm{M}, 9 \mu \mathrm{M}$, and $90 \mu \mathrm{M}) ;(\mathbf{b})$ Proportion of muropeptides released in the presence of bulgecin A relative to that released in the uninhibited reaction. ${ }^{* *} p<0.01$ (unpaired $t$-test).
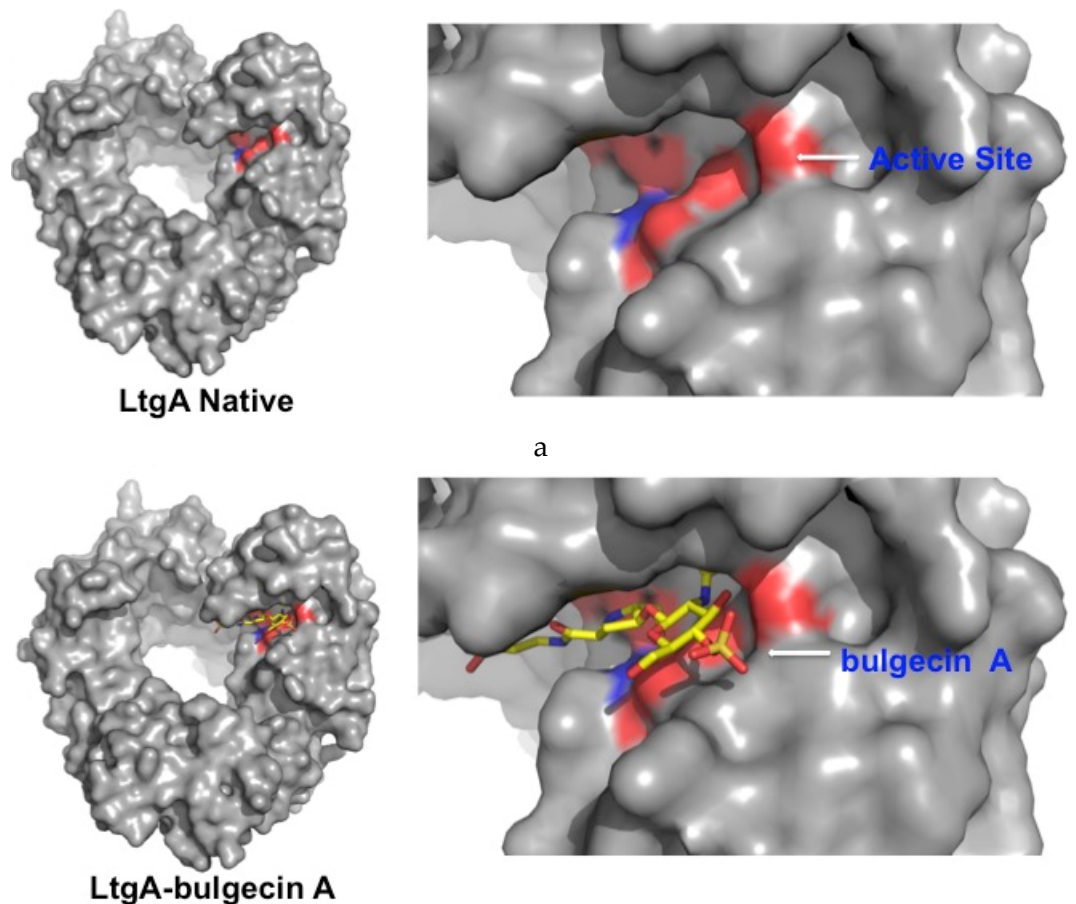

$\mathrm{b}$

Figure 4. Surface model of LtgA native and LtgA in complex with bulgecin A. (a) Conserved residues that align the active site are highlighted in red; (b) Bulgecin A binds to the conserved active site groove.

\subsection{The Effects of Bulgecin A on Viability of Neisseria sp.}

$\beta$-lactams are the antibiotic of choice for the treatment of $N$. meningitidis and N. gonorrhoeae, known as the pathogenic Neisseria. However, strains of N. meningitidis and N. gonorrhoeae have shown a reduced susceptibility to $\beta$-lactams such as penicillin $G$ and amoxicillin. Although the treatment with these two antibiotics can still be effective; the treatment doses have to be increased drastically because lower doses may lead to treatment failure [39]. The primary mechanism of reduced susceptibility to $\beta$-lactams involves polymorphism of penA, the gene that encodes PBP2 in Neisseria sp. In the past, bulgecin A has been shown to improve the efficacy of $\beta$-lactams in H. pylori and E. coli $[33,34]$. 
We extended these observations to pathogenic Neisseria sp. and showed that a combination treatment of bulgecin A with $\beta$-lactams can improve efficacy of $\beta$-lactams against pathogenic Neisseria sp. with reduced susceptibility to penicillin, i.e., Pen ${ }^{\mathrm{I}}$. We performed a basic E-test in the presence or absence of bulgecin A, with three $\beta$-lactam antibiotics (penicillin $\mathrm{G}$, amoxicillin, cefotaxime) and used chloramphenicol, an antibiotic that targets protein synthesis, as a control. We prepared agar plates with four different concentrations of bulgecin A $(0,19,38$, or $75 \mu \mathrm{g} / \mathrm{mL}$; Table 2$)$. Bulgecin A restored the efficacy of penicillin $\mathrm{G}$ and amoxicillin of $N$. meningitidis and $N$. gonorrhoeae, and lowered the minimal inhibitory concentrations (MIC) of cefotaxime against $N$. meningitidis but had little impact on the MIC of chloramphenicol (Table 2). In addition, bulgecin A in combination with $\beta$-lactams was ineffective against $\beta$-lactamase-producing resistant strain 24753 TEM-1, which strongly supports a bactericidal synergism between $\beta$-lactams and bulgecin A that may target the Slt-PBP protein complex simultaneously. It is well established that Lts and PBPs form protein complexes [18,25,28,40-42]. Most notable are the interaction between Slt70 and PBPs 1b, 1c, 2, and 3 [43]. Targeting the Slt and PBPs for future antibiotic development could potentially define a new generation of antibiotic with dual targets that are synergistic.

Table 2. The effect of $\beta$-lactams combined with bulgecin A on Neisseria species with reduced susceptibitility to $\beta$-lactams. Minimal inhibitory concentrations (MICs) $(\mu \mathrm{g} / \mathrm{mL})$ of different antibiotics are shown, in the presence of $0-75 \mu \mathrm{g} / \mathrm{mL}$ bulgecin A.

\begin{tabular}{|c|c|c|c|c|}
\hline \multicolumn{5}{|c|}{ N. gonorrhoeae Strain 24753 TEM-1 } \\
\hline \multirow{2}{*}{ Antibiotics } & \multicolumn{4}{|c|}{ Bulgecin $A(\mu g / m L)$} \\
\hline & 0 & 19 & 38 & 75 \\
\hline Penicillin G & 4 & 4 & 4 & 3 \\
\hline Amoxicillin & 16 & 12 & 16 & 12 \\
\hline Cefotaxim & 0.003 & 0.002 & 0.002 & 0.002 \\
\hline Chloramphenicol & 0.75 & 0.5 & 0.5 & 0.5 \\
\hline \multicolumn{5}{|c|}{ N. gonorrhoeae Strain 24970 Pen $^{\text {I }}$} \\
\hline & \multicolumn{4}{|c|}{ Bulgecin A $(\mu \mathrm{g} / \mathrm{mL})$} \\
\hline Antibiotics & 0 & 19 & 38 & 75 \\
\hline Penicillin G & 0.5 & 0.094 & 0.094 & 0.047 \\
\hline Amoxicillin & 0.75 & 0.38 & 0.250 & 0.19 \\
\hline Cefotaxim & 0.125 & 0.047 & 0.047 & 0.047 \\
\hline Chloramphenicol & 1.5 & 1.5 & 1 & 1 \\
\hline \multicolumn{5}{|c|}{ N. meningitidis Strain 28671 Pen $^{\mathrm{I}}$} \\
\hline \multirow{2}{*}{ Antibiotics } & \multicolumn{4}{|c|}{ Bulgecin A $(\mu \mathrm{g} / \mathrm{mL})$} \\
\hline & 0 & 19 & 38 & 75 \\
\hline Penicillin G & 0.25 & 0.095 & 0.064 & 0.047 \\
\hline Amoxicillin & 0.75 & 0.40 & 0.40 & 0.25 \\
\hline Cefotaxim & 0.125 & 0.064 & 0.064 & 0.064 \\
\hline Chloramphenicol & 0.5 & 0.5 & 0.4 & 0.5 \\
\hline
\end{tabular}

\section{Methods and Materials}

\subsection{Protein Expression and Purification}

The recombinant LtgA protein construct was created using the primers listed below and standard molecular biology techniques. The constructs used in this study were Gluthatione S-Transferase (GST)-fusions from pGEX-4T1 (GE Lifesciences). The native LtgA protein was expressed in BL21 (DE3) Gold competent cells (Novagen) and grown in Luria Broth. Recombinant LtgA protein was induced with $0.6 \mathrm{mM}$ isopropyl $\beta$-D-1-thiogalactopyranoside (IPTG) at an $\mathrm{OD}_{600}$ of $0.7-0.8$ and harvested after $4 \mathrm{~h}$ of induction at $18{ }^{\circ} \mathrm{C}$. After glutathione affinity chromatography and thrombin cleavage, proteins were purified to homogeneity by size exclusion chromatography (Superdex-200, GE Lifesciences) in $50 \mathrm{mM}$ Hepes pH 7.4, $150 \mathrm{mM} \mathrm{NaCl}$, and $1 \mathrm{mM} \beta$-mercaptoethanol (BME). After gel filtration, proteins were immediately used for crystallization. 


\subsection{Primer List}

$\operatorname{ltg} A$ Forward cgggatccacactgccagccggcaagaccceggc

$\operatorname{ltg} A$ Reverse cgaattctcagcgtgcaggaacaatgccatacgc

\subsection{Analysis of Recombinant LtgA and LtgA-GST Activity by Reversed-Phase HPLC}

LtgA activity was assessed using purified PG from N. meningitidis strain 27256 as a substrate. PG was purified as described in [44]. The PG $(100 \mu \mathrm{g})$ was incubated in the presence of $0 \mu \mathrm{M}$, $9 \mu \mathrm{M}$, or $90 \mu \mathrm{M}$ of bulgecin $\mathrm{A}$, in $12.5 \mathrm{mM}$ sodium phosphate buffer $\mathrm{pH}$ 5.6. The reaction mix was preincubated at $37^{\circ} \mathrm{C}$ for $5 \mathrm{~min}$, then the reaction was initiated by the addition of $1.4 \mu \mathrm{M} \mathrm{LtgA}$. Control reactions lacking PG or enzyme/inhibitor were also included. Total reaction volume was $200 \mu \mathrm{L}$. Reactions were performed in triplicate. Following overnight incubation at $37^{\circ} \mathrm{C}$, the reaction was stopped by incubating the samples in a boiling water bath for $3 \mathrm{~min}$. Following centrifugation at $16,000 \mathrm{~g}$ for $10 \mathrm{~min}$, the supernatant containing the soluble 1,6-anhydro-muropeptides was collected and analyzed by reversed-phase HPLC using a Shimadzu LC-20 system with a Hypersil GOLD aQ column $\left(5 \mu \mathrm{m}\right.$ particle size, $250 \times 4.6 \mathrm{~mm}$, flow rate $0.5 \mathrm{~mL} / \mathrm{mL}$ at $52{ }^{\circ} \mathrm{C}$; Thermo Fisher Scientific (Waltham, MA, USA). The mobile phase gradient was $50 \mathrm{mM}$ sodium phosphate $\mathrm{pH} 4.3$ to $75 \mathrm{mM}$ sodium phosphate $\mathrm{pH} 4.9$ with $15 \%$ Methanol over $135 \mathrm{~min}$. Muropeptide abundance was calculated as the sum of all peak areas above a baseline threshold value (20,000 units), using Shimadzu LCsolution software. We excluded peaks that appeared in the negative control reactions lacking PG, enzyme, or inhibitor, since these are not attributed to muropeptides.

\subsection{The Effects of Bulgecin A on Viability of Neisseria Species}

Etest $^{\circledR}$ (Biomérieux, Marcy l'Etoile, France) were carried out in duplicate by plating a lawn of the relevant Neisseria species onto Giolitti-Cantoni Broth (GCB) agar with Kellogg supplements plus [45] $0,19,38$, or $75 \mu \mathrm{g} / \mathrm{mL}$ bulgecin A. Etest ${ }^{\circledR}$ analyses were performed for three $\beta$-lactams: penicillin $\mathrm{G}$, amoxicillin, and cefotaxim. Chloramphenicol was used as a non- $\beta$-lactam control. Three strains were used in this study, (1) N. gonorrhoeae Strain 24753 TEM-1; (2) N. gonorrhoeae Strain 24970 Pen'; (3) N. meningitidis Strain 28671 Pen $^{\mathrm{I}}$.

\subsection{X-ray Crystallography}

Crystallization screening was carried out by the sitting drop vapor diffusion method with a Mosquito ${ }^{\circledR}$ (TTP Labtech) automated crystallization system. All crystals were grown at $18^{\circ} \mathrm{C}$ using the hanging-drop vapor diffusion method. Crystals of $\operatorname{Ltg} \mathrm{A}$ were grown at $18{ }^{\circ} \mathrm{C}$ and appeared within 2-3 days. The concentration of $\operatorname{Ltg} A$ was between $20-25 \mathrm{mg} / \mathrm{mL}$. LtgA was crystallized in 1:1 (v/v) ratio against a well solution of 1.5-2.0 M ammonium sulfate, 0.1 4-Morpholineethanesulfonic acid buffer (MES) buffer pH 6.5 or 1.5-2.0 M ammonium sulfate, $0.1 \mathrm{M} 2 \%(\mathrm{v} / \mathrm{v})$ polyethylene glycol (PEG) 400 0.1 M Hepes pH 7.5. Crystals were rectangular in shape and grew to about 200-300 microns in length. To generate LtgA-bulgecin A complex, the native crystals of LtgA were soaked with a 10-fold molar excess of bulgecin A for $3 \mathrm{~h}$ and flash-cooled. Crystals were cryoprotected in a mixture of $50 \%$ Paratone and 50\% Paraffin oils and flash-cooled in liquid nitrogen.

Phasing by LtgA-Bulgecin A complex was accomplished by molecular replacement using LtgA Native (4YIM) Phenix [46]. Building was performed using Coot [47], and restrained refinement was carried out using a combination of Phenix and a ccp4 software suite [46,48]. Molprobity was used during building and refinement for iterative structure improvements [49]. All structural figures were generated with Pymol (the PyMOL Molecular Graphics System, Version 1.5, Schrödinger, LLC, Cambridge, UK). The crystallographic parameters, data statistics, and refinement statistics are shown in Table 1. Coordinates and structure factors of LgtA-bulgecin A and LgtA mutant have been deposited in the Protein Data Bank (PDB) with the accession codes 5MPQ. 


\subsection{Docking Studies}

The LtgA-chitopentaose complex was created using the MltE-chitopentaose (Protein Data Bank (PDB) ID: 4HJY) as a scaffold. Alignment of LtgA to MltE chitopentaose was done in Coot [47]. The full LtgA-chitopentaose complex was refined against the structure factors of MltE-chitopentaose complex using the ccp4 software, refmac [47]. The complex was examined and further positioned in Coot to facilitate chemical and geometric accuracy.

\subsection{Sequence Alignments}

The c-domain of LtgA and E. coli Slt70 were aligned with DNAstar Lasergene software (DNAstar, Madison, WI, USA) and its MegaAlign module using Clustal W.

\section{Conclusions}

Since antimicrobial resistance is a serious global threat, it is time to pursue different therapies to eradicate the most dangerous pathogens. The over-dependence on $\beta$-lactams is a key contributor to the rise of drug-resistant strains. LtgA is conserved across all species of Neisseria. N. gonorrhoeae LtgA shares a 98 percent similarity to $N$. meningitidis LtgA. There are successful vaccines that target $N$. meningitidis, however, as there are no available vaccines to fight $N$. gonorrhoeae infection, treatment has relied solely on antibiotic therapies. There is an increasing emergence of drug resistance in N. gonorrhoeae that underlines the need for new therapeutic molecules. Indeed, N. gonorrhoeae with resistance to all antibiotics used currently for treatment (super bug) are anticipated [44]. Our study demonstrates that $N$. meningitides susceptibility to $\beta$-lactams is restored in the presence of bulgecin A. The clinical breakpoint for penicillin $\mathrm{G}$ recommended by the European monitoring group (EMGM) on N. meningitidis is below $0.125 \mu \mathrm{g} / \mathrm{mL}$ for susceptibility, and greater than $1 \mu \mathrm{g} / \mathrm{mL}$ for resistance [39]. Already, the lowest concentration of bulgecin A $(19 \mu \mathrm{g} / \mathrm{mL})$ restored the susceptibility of $N$. meningitidis strain 28,671 Pen ${ }^{\mathrm{I}}$ to below the susceptibility break-point $(0.047 \mu \mathrm{g} / \mathrm{mL})$. So far, $\beta$-lactams show improved efficacy in the presence of bulgecin A against H. pylori, E. coli, P. aeruginosa, A. baumannii, and now N. meningitidis and N. gonorrhoeae. The high-resolution structure of LtgA in complex with bulgecin A can be used to rationally design inhibitory molecules that target Lts in general. We propose the use of bulgecin A in combination with $\beta$-lactams as a new therapeutic strategy to fight antimicrobial resistance.

Supplementary Materials: The following are available online at http://www.mdpi.com/2079-6382/6/1/8/s1, Figure S1: (a) Ribbon model of LtgA highlighting the conserved U (green), L (orange), and C (grey) domains. The catalytic residue of LtgA E481 is shown in black; (b) Secondary structure of Slt70. The domain organization of $\operatorname{Ltg} \mathrm{A}$ represented by cylinders is close to S1t70, the soluble lytic transglycosylase from E. coli, Figure S2: The final $\mathrm{F}_{\mathrm{O}}-\mathrm{F}_{\mathrm{C}}$ electron density map of bulgecin A contoured at 3 sigma. The final $2 \mathrm{~F}_{\mathrm{O}}-\mathrm{F}_{\mathrm{C}}$ map of LtgA contoured at 2 sigma, Figure S3: The catalytic domain of lytic transglycosylases is highly conserved, Figure S4: Bulgecin A occupies the active site of LtgA, Figure S5: Sequence alignment of the C-domain of LtgA and Slt70.

Acknowledgments: We would like to thank the beamlines staff (PROXIMA-1at SOLEIL and X06DA at Swiss Light Source) for their assistance. We are continually grateful to Frederick Saul, Patrick Weber, and Marco Bellinzoni for helpful advice and assistance. We thank Antoine Forget for helpful advice and help with figure presentations. Allison H. Williams was supported by an EMBO long-term fellowship (ALTF 732-2010) and an Institut Carnot-Pasteur Maladies Infectieuses fellowship. This work was supported by an ERC starting grant (PGNfromSHAPEtoVIR 202283) to Ivo Gomperts Boneca and an ANR (Agence National de la Recherche) grant number ANR-14-CE14-0003 to MKT. This study has received funding from the French Government's Investissement d'Avenir program, Laboratoire d'Excellence "Integrative Biology of Emerging Infectious Diseases" (grant $n^{\circ}$ ANR-10-LABX-62-IBEID).

Author Contributions: Allison H. Williams and Ivo G. Boneca designed the research. Allison H. Williams and Constance Thiriau purified and biochemically characterized the protein. Richard Wheeler conducted HPLC enzyme assays. Allison H. Williams and Ahmed Haouz conducted all structural experiments. Ahmed Haouz collected X-ray data. Allison H. Williams solved and refined all structures. Muhamed-Kheir Taha conducted biological validation of the structural studies. Allison H. Williams and Ivo G. Boneca analyzed all data. Allison H. Williams wrote the manuscript. All authors contributed to the editing of the article.

Conflicts of Interest: The authors declare no conflict of interest. 


\section{References}

1. Blair, J.M.; Webber, M.A.; Baylay, A.J.; Ogbolu, D.O.; Piddock, L.J. Molecular mechanisms of antibiotic resistance. Nat. Rev. Microbiol. 2015, 13, 42-51. [CrossRef] [PubMed]

2. Fair, R.J.; Tor, Y. Antibiotics and bacterial resistance in the 21st century. Perspect. Medicin. Chem. 2014, 6, 25-64. [PubMed]

3. Cho, H.; Uehara, T.; Bernhardt, T.G. Beta-lactam antibiotics induce a lethal malfunctioning of the bacterial cell wall synthesis machinery. Cell 2014, 159, 1300-1311. [CrossRef] [PubMed]

4. Artola-Recolons, C.; Carrasco-López, C.; Llarrull, L.I.; Kumarasiri, M.; Lastochkin, E.; Martínez de Ilarduya, I.; Meindl, K.; Usón, I.; Mobashery, S.; et al. High-resolution crystal structure of MltE, an outer membrane-anchored endolytic peptidoglycan lytic transglycosylase from Escherichia coli. Biochemistry 2011, 50, 2384-2386. [CrossRef] [PubMed]

5. Bateman, A.; Bycroft, M. The structure of a LysM domain from E. coli membrane-bound lytic murein transglycosylase D (MltD). J. Mol. Biol. 2000, 299, 1113-1119. [CrossRef] [PubMed]

6. Madoori, P.K.; Thunnissen, A.M. Purification, crystallization and preliminary X-ray diffraction analysis of the lytic transglycosylase MltF from Escherichia coli. Acta Crystallogr. Sect. F Struct. Biol. Cryst. Commun. 2010, 66, 534-538. [CrossRef] [PubMed]

7. Lommatzsch, J.; Templin, M.F.; Kraft, A.R.; Vollmer, W.; Höltje, J.V. Outer membrane localization of murein hydrolases: MltA, a third lipoprotein lytic transglycosylase in Escherichia coli. J. Bacteriol. 1997, 179, 5465-5470. [CrossRef] [PubMed]

8. Artola-Recolons, C.; Lee, M.; Bernardo-García, N.; Blázquez, B.; Hesek, D.; Bartual, S.G.; Mahasenan, K.V.; Lastochkin, E.; Pi, H.; Boggess, B.; et al. Structure and cell wall cleavage by modular lytic transglycosylase MltC of Escherichia coli. ACS Chem. Biol. 2014, 9, 2058-2066. [CrossRef] [PubMed]

9. Thunnissen, A.M.; Dijkstra, A.J.; Kalk, K.H.; Rozeboom, H.J.; Engel, H.; Keck, W.; Dijkstra, B.W. Doughnut-shaped structure of a bacterial muramidase revealed by X-ray crystallography. Nature 1994, 367, 750-753. [CrossRef] [PubMed]

10. Thunnissen, A.M.; Isaacs, N.W.; Dijkstra, B.W. The catalytic domain of a bacterial lytic transglycosylase defines a novel class of lysozymes. Proteins 1995, 22, 245-258. [CrossRef] [PubMed]

11. Cloud, K.A.; Dillard, J.P. A lytic transglycosylase of Neisseria gonorrhoeae is involved in peptidoglycan-derived cytotoxin production. Infect. Immun. 2002, 70, 2752-2757. [CrossRef] [PubMed]

12. Cloud, K.A.; Dillard, J.P. Mutation of a single lytic transglycosylase causes aberrant septation and inhibits cell separation of Neisseria gonorrhoeae. J. Bacteriol. 2004, 186, 7811-7814. [CrossRef] [PubMed]

13. Woodhams, K.L.; Chan, J.M.; Lenz, J.D.; Hackett, K.T.; Dillard, J.P. Peptidoglycan fragment release from Neisseria meningitidis. Infect. Immun. 2013, 81, 3490-3498. [CrossRef] [PubMed]

14. Girardin, S.E.; Travassos, L.H.; Hervé, M.; Blanot, D.; Boneca, I.G.; Philpott, D.J.; Sansonetti, P.J.; Mengin-Lecreulx, D. Peptidoglycan molecular requirements allowing detection by Nod1 and Nod2. J. Biol. Chem. 2003, 278, 41702-41708. [CrossRef] [PubMed]

15. Girardin, S.E.; Boneca, I.G.; Carneiro, L.A.M.; Antignac, A.; Jéhanno, M.; Viala, J.; Tedin, K.; Taha, M.K.; Labigne, A.; Zaehringer, U.; et al. Nod1 detects a unique muropeptide from gram-negative bacterial peptidoglycan. Science 2003, 300, 1584-1587. [CrossRef] [PubMed]

16. Girardin, S.E.; Boneca, I.G.; Chamaillard, M.; Labigne, A.; Thomas, G.; Philpott, D.J.; Sansonetti, P.J. Nod2 is a general sensor of peptidoglycan through muramyl dipeptide (MDP) detection. J. Biol. Chem. 2003, 278, 8869-8872. [CrossRef] [PubMed]

17. Viala, J.; Chaput, C.; Boneca, I.G.; Cardona, A.; Girardin, S.E.; Moran, A.P.; Athman, R.; Mémet, S.; Huerre, M.; Coyle, A.J. Nod1 responds to peptidoglycan delivered by the Helicobacter pylori cag pathogenicity island. Nat. Immunol. 2004, 5, 1166-1174. [CrossRef] [PubMed]

18. Van Heijenoort, J. Peptidoglycan hydrolases of Escherichia coli. Microbiol. Mol. Biol. Rev. 2011, 75, 636-663. [CrossRef] [PubMed]

19. Kohler, P.L.; Hamilton, H.L.; Cloud-Hansen, K.; Dillard, J.P. AtlA functions as a peptidoglycan lytic transglycosylase in the Neisseria gonorrhoeae type IV secretion system. J. Bacteriol. 2007, 189, 5421-5428. [CrossRef] [PubMed] 
20. Cloud-Hansen, K.A.; Hackett, K.T.; Garcia, D.L.; Dillard, J.P. Neisseria gonorrhoeae uses two lytic transglycosylases to produce cytotoxic peptidoglycan monomers. J. Bacteriol. 2008, 190, 5989-5994. [CrossRef] [PubMed]

21. Chan, Y.A.; Hackett, K.T.; Dillard, J.P. The lytic transglycosylases of Neisseria gonorrhoeae. Microb. Drug. Resist. 2012, 18, 271-279. [CrossRef] [PubMed]

22. Schaub, R.E.; Chan, Y.A.; Lee, M.; Hesek, D.; Mobashery, S.; Dillard, J.P. Lytic transglycosylases LtgA and LtgD perform distinct roles in remodeling, recycling and releasing peptidoglycan in Neisseria gonorrhoeae. Mol. Microbiol. 2016, 102, 865-881. [CrossRef] [PubMed]

23. Santin, Y.G.; Cascales, E. Domestication of a housekeeping transglycosylase for assembly of a Type VI secretion system. EMBO Rep. 2017, 18, 138-149. [CrossRef] [PubMed]

24. Vollmer, W.; Holtje, J.V. The architecture of the murein (peptidoglycan) in gram-negative bacteria: Vertical scaffold or horizontal layer(s)? J. Bacteriol. 2004, 186, 5978-5987. [CrossRef] [PubMed]

25. Vollmer, W.; Joris, B.; Charlier, P.; Foster, S. Bacterial peptidoglycan (murein) hydrolases. FEMS Microbiol. Rev. 2008, 32, 259-286. [CrossRef] [PubMed]

26. Vollmer, W.; Blanot, D.; de Pedro, M.A. Peptidoglycan structure and architecture. FEMS Microbiol. Rev. 2008, 32, 149-167. [CrossRef] [PubMed]

27. Vollmer, W. Structural variation in the glycan strands of bacterial peptidoglycan. FEMS Microbiol. Rev. 2008, 32, 287-306. [CrossRef] [PubMed]

28. Vollmer, W.; Bertsche, U. Murein (peptidoglycan) structure, architecture and biosynthesis in Escherichia coli. Biochim. Biophys. Acta 2008, 1778, 1714-1734. [CrossRef] [PubMed]

29. Scheurwater, E.; Reid, C.W.; Clarke, A.J. Lytic transglycosylases: Bacterial space-making autolysins. Int. J. Biochem. Cell Biol. 2008, 40, 586-591. [CrossRef] [PubMed]

30. Van Asselt, E.J.; Thunnissen, A.M.; Dijkstra, B.W. High resolution crystal structures of the Escherichia coli lytic transglycosylase Slt70 and its complex with a peptidoglycan fragment. J. Mol. Biol. 1999, 291, 877-898. [CrossRef] [PubMed]

31. Reid, C.W.; Blackburn, N.T.; Legaree, B.A.; Auzanneau, F.I.; Clarke, A.J. Inhibition of membrane-bound lytic transglycosylase B by NAG-thiazoline. FEBS Lett. 2004, 574, 73-79. [CrossRef] [PubMed]

32. Van Asselt, E.J.; Dijkstra, B.W. Binding of calcium in the EF-hand of Escherichia coli lytic transglycosylase Slt35 is important for stability. FEBS Lett. 1999, 458, 429-435. [CrossRef]

33. Templin, M.F.; Edwards, D.H.; Holtje, J.V. A murein hydrolase is the specific target of bulgecin in Escherichia coli. J. Biol. Chem. 1992, 267, 20039-20043. [PubMed]

34. Bonis, M.; Williams, A.H.; Guadagnini, S.; Werts, C.; Boneca, I.G. The effect of bulgecin A on peptidoglycan metabolism and physiology of Helicobacter pylori. Microb. Drug. Resist. 2012, 18, 230-239. [CrossRef] [PubMed]

35. Thunnissen, A.M.; Rozeboom, H.J.; Kalk, K.H.; Dijkstra, B.W. Structure of the 70-kDa soluble lytic transglycosylase complexed with bulgecin A. Implications for the enzymatic mechanism. Biochemistry 1995, 34, 12729-12737. [CrossRef] [PubMed]

36. Skalweit, M.J.; Li, M. Bulgecin A as a beta-lactam enhancer for carbapenem-resistant Pseudomonas aeruginosa and carbapenem-resistant Acinetobacter baumannii clinical isolates containing various resistance mechanisms. Drug. Des. Devel. Ther. 2016, 10, 3013-3020. [CrossRef] [PubMed]

37. Antignac, A.; Kriz, P.; Tzanakaki, G.; Alonso, J.M.; Taha, M.K. Polymorphism of Neisseria meningitidis penA gene associated with reduced susceptibility to penicillin. J. Antimicrob. Chemother. 2001, 47, $285-296$. [CrossRef] [PubMed]

38. Antignac, A.; Boneca, I.G.; Rousselle, J.C.; Namane, A.; Carlier, J.P.; Vazquez, J.; Fox, A.; Alonso, J.M.; Taha, M.K. Correlation between alterations of the penicillin-binding protein 2 and modifications of the peptidoglycan structure in Neisseria meningitidis with reduced susceptibility to penicillin G. J. Biol. Chem. 2003, 278, 31529-31535. [CrossRef] [PubMed]

39. Belkacem, N.; Hong, E.; Antunes, A.; Terrade, A.; Deghmane, A.E.; Taha, M.K. Use of Animal models to support revising meningococcal breakpoints of beta-lactams. Antimicrob. Agents Chemother. 2016, 60, 4023-4027. [CrossRef] [PubMed]

40. Dijkstra, B.W.; Thunnissen, A.M. "Holy" proteins. II: The soluble lytic transglycosylase. Curr. Opin. Struct. Biol. 1994, 4, 810-813. [CrossRef] 
41. Romeis, T.; Holtje, J.V. Specific interaction of penicillin-binding proteins 3 and $7 / 8$ with soluble lytic transglycosylase in Escherichia coli. J. Biol. Chem. 1994, 269, 21603-21607. [PubMed]

42. Legaree, B.A.; Clarke, A.J. Interaction of penicillin-binding protein 2 with soluble lytic transglycosylase B1 in Pseudomonas aeruginosa. J. Bacteriol. 2008, 190, 6922-6926. [CrossRef] [PubMed]

43. Von Rechenberg, M.; Ursinus, A.; Holtje, J.V. Affinity chromatography as a means to study multienzyme complexes involved in murein synthesis. Microb. Drug. Resist. 1996, 2, 155-157. [CrossRef] [PubMed]

44. Wheeler, R.; Veyrier, F.; Werts, C.; Boneca, I.G. Peptidoglycan and nod receptor. In Glycoscience: Biology and Medicine; Taniguchi, N., Endo, T., Hart, G.W., Seeberger, P.H., Wong, C.-H., Eds.; Springer: Tokyo, Japan, 2014; pp. 737-747.

45. Kellogg, D.S., Jr.; Peacock, W.L., Jr; Deacon, W.E.; Brown, L.; Pirkle, D.I. Neisseria Gonorrhoeae. I. Virulence genetically linked to clonal variation. J. Bacteriol. 1963, 85, 1274-1279. [PubMed]

46. Adams, P.D.; Afonine, P.V.; Bunkóczi, G.; Chen, V.B.; Davis, I.W.; Echols, N.; Headd, J.J.; Hung, L.W.; Kapral, G.J.; Grosse-Kunstleve, R.W.; et al. PHENIX: A comprehensive python-based system for macromolecular structure solution. Acta Crystallogr. D Biol. Crystallogr. 2010, 66, 213-221. [CrossRef] [PubMed]

47. Emsley, P.; Cowtan, K. Coot: Model-building tools for molecular graphics. Acta Crystallogr. D Biol. Crystallogr. 2004, 60, 2126-2132. [CrossRef] [PubMed]

48. Collaborative, C.P. The CCP4 suite: Programs for protein crystallography. Acta Crystallogr. D Biol. Crystallogr. 1994, 50, 760-763.

49. Davis, I.W.; Murray, L.W.; Richardson, J.S.; Richardson, D.C. MOLPROBITY: Structure validation and all-atom contact analysis for nucleic acids and their complexes. Nucleic. Acids Res. 2004, 32, W615-W619. [CrossRef] [PubMed]

(C) 2017 by the authors. Licensee MDPI, Basel, Switzerland. This article is an open access article distributed under the terms and conditions of the Creative Commons Attribution (CC BY) license (http:/ / creativecommons.org/licenses/by/4.0/). 